\title{
Specialization \& Personalization of Pay TV Channel
}

\author{
Fanbin Zeng (Corresponding author) \\ College of Journalism and Communication, Jinan University, Guangzhou 510632, China \\ E-mail: zengfanbin@vip.sina.com \\ Ruini Liu \\ College of Journalism and Communication, Jinan University, Guangzhou 510632, China \\ E-mail: louder0000@gmail.com
}

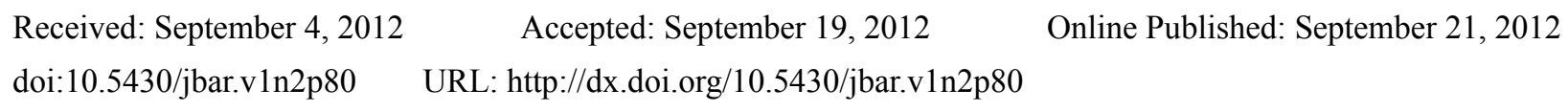

This Project was financed by 2012 Humanities and Social Science Youth Foundation of the Ministry of Education of China (Grant Number: 12YJC860052; Grant Title: Effect of Time Spent Online and Patterns of internet use on Real-life Political Participation: Based on Empirical Study on Internet Users in Guangzhou)

\begin{abstract}
As a specialized and even personalized television channel, Pay TV should provide more personal, professional, attractive and ample content to a carefully segmented market. This article attempts to carry out a discussion of the practice of the specialization and personalization of Pay TV Channel.
\end{abstract}

Keywords: Specialization, Personalization, Segmentation, Pay TV, Free TV

\section{Comprehensiveness and Popularity of Free Television Channel}

Free TV Channels are free of charge, so most of their revenue and fees for purchase of equipments and production of programs are raised from advertisements. Since that, the popularity of the program contributes directly to the investment of the advertisers, who care about the attention of the program instead of the content itself.

When designing a program, Free TV operators would take two factors into consideration:

Firstly, according to the law of large numbers, which requires the maximization of audiences to maximize the effect of advertisement, TV programs should cater to the public taste. The most important feature of popular programs is to satisfy the broadest appeal point of audiences, which would aim to be at the top of the lists of the rank to every individual's favorites. It's certain that every individual shares different preferences and trails so that their taste of programs would be distinctive and sometimes even contradictory. Since that, popular programs probably would be the first choice of the majority but not everyone. In a word, the efforts of Free TV operators are not pointed at "the most satisfactory" audiences, but for "the largest number" of them;

Secondly, some programs of Free TV channels are designed especially for advertisers and mostly based on the like of their targeting audiences to better convey information for advertisers to boost their sales, then in return, earn more revenue.

Thirdly, its commonality and node-to-surface propagation mode determine that Free TV channels could not satisfy every individual's need but the utmost approval of audiences as a whole. Its audiences are the masses, which vary from age, sex, income and interest. As a result, mostly, a majority of audiences would not gain 100 percent satisfaction from the content of Free TV programs;

Fourthly, in terms of business pattern, Free TV channels earn most of their profit from advertisers. And in terms of target audiences, every audience would count. But pursuing popularity, it must give up on part of audiences and ignore their individual needs. In Free TV system, due to the broadness and commonality of programs, its target audiences are ambiguous, undefined and unstable, mixing up with lots of contingency factors.

To conclusion, Free TV channels would fight for largest scale market, while Pay Television channels would compete for a market where requires more personalization and specialization. 


\section{Specialization of Pay TV and Market Segmentation}

Specialization, mainly about the media positioning, is not only to specialize or object-oriented the programs, but also about the positioning of media based on the audience segmentation. Only when the targeted audiences are clarified can the Pay TV service be more accurate and effective to satisfy their needs. The specialization of Pay TV channels means that the channels position themselves according to the categorization of audiences and provide content to subscribers for their specific needs. Pay TV specialization includes two aspects: One is the specialization of content, which means to focus on just one special type of TV programs, such as existing channels like sports, variety shows and economics, but eventually these categories will go deep into the segmented trend of TV channel and become more and more specific, such as sports channels of go, football and basketball; The other is the specialization of object, namely target audiences, which means the channel aims more specifically to a certain group of audiences, like doctors and lawyers. Take a Children's television channels in France, which was launched in 1990 especially for children aged form 2 years old to 14 . It takes 13 hours every day to broadcast exclusively the children's programs, founded a children's club, to interviews with experts helping to solve the problems put forward by children or their parents, and organizes children for travels.

To achieve specialization, Pay TV channels need to segment the market and products to better serve the interests of customers. Markets can be segmented according to age, gender, religion, class, etc., while products are divided by the interest and preference of audiences and arranged in content.

Take CCTV6 Movie Channel. It is a subordinate TV station of Chinese Central Television (CCTV). It caters to all audience, and all programs are related to film, including movies and other columns, as well as live of major awards ceremony of domestic and international. It could be sorted to the categories of specialized channels for movies but a popularized one, at the primary stage of the professional channel types. While $\mathrm{CHC}$ action movie channel has developed to an advanced stage in subdividing the categories of films and only action movies are broadcasted. Because its targeting audiences are narrowed to a minority of people who like movies about criminal, war, horror, science fiction, so it can be refined as a Pay TV channel targeting a more specific group and more specialized.

We can see how the Pay TV channels are segmented though the show list of British BskyB sky TV: football, golf, American Football, Wrestling, Boxing, Basketball, Baseball, etc. for Sports channels; Music, Pop, Documentary, Performance, Movie, Gambling, Fashion, Adult Information etc. for Entertainment channels; Financial, Real Estate, Stock, Shopping etc. for Economic channels; Parliament, God, National Defense, etc. for other channels. From our audience's point of view, this segmentation has been rather specified and the target groups are concentrated. Yet for British people, these are far from enough. They would subdivide the Music channel further to Rock, Classical, Pop, Country music, Jazz, etc.; Movies to Classics, New Movie, Category III Movies, etc; Documentary channels to Discovery, National Geographic, the History; Performance channel to the Drama, Opera, Ballet; Shopping channel to Fashion clothes, Jewelry, Household Objects, Car, Science and Technology Products; Adult Information to Audio, Video, Advertising, etc. (Website: http://www.sky.com/). As can be seen, British Sky TV Pay TV channels have reached not only mass decentralization but minority-orientation. It has developed a set of specific hierarchical fees charge system and involves relatively vast professional knowledge and practical information for their content, which are worthy for audiences who pay for their preferences as well as China's Pay TV channels' references.

Pay TV channel must seek appropriate market segmentation and the selling point of content. Compared with the traditional Free TV channel, differentiation and specialization are highlighted by Pay TV and so does more clear audience positioning. The survival of a Pay TV attributes to sufficient audiences. The establishment of a specialized Pay TV channel should be in line with the values and needs of the segmented and restricted audiences based on fully market survey. Therefore, how to find both a topic of the channel and market segment that is suitable for survival in the competitive market becomes the primary issue.

\section{Personalization of Pay TV and Its Features}

Personalization enables the channel to provide complete media information service for a specific group to satisfy their entertainment and information demand more fully, and therefore make it easier to build the audience loyalty. To be personalization should not only provide sufficient but attractive information for oriented-audience. In this respect, SMG(short for Shanghai Media Group) and Hunan Satellite TV of China have the consciousness to provide personalized service more or less, which have had obtained certain effect. The brand design of CBN (short for China Business News) of SMG, which aims at male investors, emphasizes to "provide real-time, rigorous, high-quality financial information for a vast number of Chinese investors and Chinese economic circle". According to the positioning, CBN shift its main focus to investment-relevant information programs instead of its previous make-it-large-and-all-conclusive target. Its audience positioning also reflects on the program style, which becomes 
more decent and solemn. Theses won CBN the favor of investors. Some investment companies even set a TV in office that only play CBN during work. Hunan Satellite Television claims to set a "most vigorous TV entertainment brand in China". The interpretation of being "vigorous" of Hunan Satellite TV is not all generalities of entertainment content, but content that will win the favor of the fashion youth, especially female teenagers under 25 years old, which can be reflected on the staple programs and their hosting style, like those of Happy Camp, Date of Rose, Super Girl, Dae Jang Geum etc. As a Free TV, its personalization obtained the increase of the viewing ratio. And for a Pay TV channel, to make the programs personalized is of the same necessity to enhance the intentions of users to pay.

Though a novel positioning lays the foundation of the personalization of a channel, yet the enduring mysteries in a channel are the original and unique contents. Take the Games Channel of Liaoning TV. It's much professionalized. However, its programs are still much the same as those of over-the-air TV, in the aspects of both the layout and form. In opposite, Pay TV channels which provide original and self-produced programs, especially the ones broadcasted in the prime time, are unique in both content and program form to attract audiences more successfully.

At present, Pay TV channels in China are divided by their specialization, where an audience should seek different channels for programs he likes, lessening the utilization of each channel. And according to the practice of the promotion, it's hard for audiences to accept this partition method. Since that, to personalize the channel, which enables the audiences to pay for just one or few channels to satisfy individual needs of deferent type's, is more acceptable and therefore increase the intention to pay.

The most difficult part of the personalization of a channel is the subdivision of audiences and the analysis on needs of specific groups. The simple way is to divide audiences according to the demography, like male and female, the elder and the young, high-educated persons and lower ones, etc., which is straight forward and convenient for operating as well as promoting. But the interests of people are not necessarily relevant to their gender or age. For instance, people from different age groups might be interested in a same program and those who are at the same age might prefer different types of channels. Thus, subdividing audiences on the basis of demography would not fit in the needs enough.

One of the important approaches to subdivide the personalized audiences would be the data mining of the viewing ratio. Data mining is the most dynamic subfield of current statistics study, which is to identify the potential statistical model of data through analysis of extensive data. Viewing ratio, the most important data of television industry, contains all the sample users' detailed information of all types of programs they watched. In general, only the collection of the viewing data-most commonly used data like ratings and household share, are concerned, but not individual viewing behavior, which needs further studies. For example, information about an individual audience that what kinds of programs he/she has watched in past few years, is he/she watched certain program accidentally or regularly, did he/she watch the completion of the program or intermittently, are important to unearth his/her interests and hobbies. Combining individual information lengthways, we could get the watching demand combination of programs for each audience, so as to be the guidance to provide tailored program packages for certain kinds of audiences. Data mining can help to divide tens of thousands of sample audiences into several types according to their viewing habits, and each audience type is corresponding to a program combination, of which the larger number would become target audiences of a certain personalized channel. Therefore, data mining will be the most important application of ratings data to excavate the target population. Operators who can identify new type of target population would provide the most suitable program combination for them, thereby winning the loyalty of them (Gong, Jianghui, 2008).

\section{Reasons of the Existing Problems of Pay TVs}

The lack of in-depth investigations of audiences leads to the truth that many existing Pay TV channels in China are not audience-oriented. Also, when choosing fields for specialization, many of the Pay TV channels still are in accordance with the traditional standards, such as Economy, Life, Sports, Entertainment, Films, TV programs and other simple cluster, but not concerning their characteristics and advantages, contributing to the obscure, unreasonable even superposition strategic orientation. Firstly, Pay TVs in China flock together in identical channels like channels for films, life, shopping etc. Take shopping channels, there are up to 16 choices. Secondly, the quality of Pay TV channels' programs is inconsistent with the expectation. In daily broadcast of some professional channels, there might be only a few hours out of over ten hours where the content is related to the "profession". Ethnic songs and dances are playing in Health channel, entertainment programs in Lottery channel, folktales in Opera channel, piles of shopping advertisements in Art channel, etc. Digital Pay TV channels are accepted by TV industries as having vast development potential, which are specialized in certain field. Yet the truth is, the orientation of Pay TV channels is in such a mass that some are even dismissed as "rubbish" by audiences (Li, Yang \& Sheng, Yu, 2009). 
Why problems emerged like these? There are reasons as following:

\subsection{Obstacle from the Traditional TV Production System}

In China, most of the Pay TV channels are owned by national, provincial or municipal television, which determine that quite a number of the channels continue to use the traditional management mode but not a new system that adapt to the development of digital Pay TV production. In particular, traditional TV production system-- Combination of Manufacture and Broadcast, has been the crucial obstacle of the improvement of both the quality and the quantity of programs.

Combination of Manufacture and Broadcast is an operating system where all parts of the production, including design of programs, investment, manufacturing, censor and broadcast etc., are operated by program apartment of television station (Tang, Shiding \& Li, Bin, 2005). Another kind of producing system is Separation of Manufacture and Broadcast, dammed from the English word "Commission", originally meaning that the TV broadcast institution commission some programs to an independent producer or production company to manufacture, which exits only as a supplement of producing system in China. The situation that Combination of Manufacture and Broadcast plays as the main body of the production would easily lead to the bloat and overstaffing, resulting in complicated apartment structures, overlapping function and lower efficiency. Besides propaganda programs, most of the television shows would be set aside by TV station for backup instead of business, which brings about the circulation of high input and investment but low output and income. In addition, many TV stations are not cost-conscious, throwing money that leads to huge waste and overspend but still producing programs of uneven quality. What's more, there would be no platform to attract talents for participation into TV industry of rigid formation. Because Separation of Manufacture and Broadcast exists only as supplement, the status of institutes that produce programs and that broadcast are unequal. The buyer, TV stations, are in the relatively monopoly position where it has certain rights to control the price of programs in the market, while the seller, the programs production institutions, especially private ones, are living a tougher life (Tang, Shiding \& Li, Bin, 2009).

Digital Pay TV channels set high demand for the professionalization, competiveness and the well-targeted of programs, which are of great shortage in traditional TV. In traditional TV, programs are manufactured in a great quantity for immediate sales. There are generally two types of funders of Pay TV channels. First kind is channels fund by Television station owned by state, province, provincial capital cities and Cities with independent planning, or channels fund by CCTV, SMG, BeiGuang Media Group and Movie Channel Center, four biggest integrated platform in China, channels fund by other levels of television station that don't have the integration platform; Second is channels fund by non-TV institutions like Radio Station and Film Factory, such as the China National Radio, Central News Film Studio.

Many Pay TV channels fund by all levels of TV stations are of small scale, flat strength, and relative shortage of content resource. Their capacity of producing and manufacturing programs is low, producing programs of insufficient quantities and inferior quality, which would not reach the high demand of Pay TV channel. Let alone the non-TV institutions. Besides, the relationship among televisions owned by country and the provinces and cities are so loose that provincial radio and television stations have little content. And the existing competition between TV stations of provinces and cities incapacitate the program exchange, which leads to greater shortage of programs of Pay TV channels.

\subsection{Low Revenue Results in Insufficient Investment}

Insufficient investment brought about by low revenue would prevent Digital Pay TV from entering in the well-developed path quickly. Capital has become the key factor for all sorts of industries nowadays, without which everything could not function. As a newborn industry, the first problem stood on the path of Digital Pay TV would be the shortage of capital, much the same as the burning money period when the internet sprung up.

The operation of Pay TV channels needs abundant capital for every single link, from the set-up to daily operation. Using the experience of other countries for reference, the production expense for Digital Pay TV usually would generally be 4 times the costs of digital equipments, which would be up to 100 billion. Data shows that the cost of a Digital Pay TV is summed up to from 7 million to 10 million Yuan a year, which are accumulated amongst the progress (Yin, Liangrun, 2009). Among the expense, $20 \%$ is for labor, $70 \%$ for purchase of progress and equipments, $10 \%$ for transportation and maintenance.

In fact, the investment of a virtual channel of higher viewing ratios is among 50 billion and 100 billion, which is not that expensive for the funders who have already putting tens of billions into existing Pay TV channels. Domestic Pay TV channels are fund by TV stations of provinces and cities, where the earning of Pay TV channel is obviously 
relatively low comparing with advertising revenue. In 2007, the business sales of more than 120 domestic digital Pay TV channels are only 150 million Yuan, while in 2006, the advertising revenue of all radio and television stations have reached 52.7 billion Yuan (Xu, Yaowen, 2008). Digital Pay TV channels in the incubation period have less market demand and users, leading to little economic benefits and low rate of fund return, which in return resulting in the income of Pay TV channels is always hanging in low level and could not start an optimum cycle of capital. Compared with open channels, Digital Pay TV channels are facing huge financial pressure.

\subsection{The Policy Restrictions for the Supply of Pay TV Channels}

Policy restrictions also make the Pay TV channels difficult to purchase more professional, personalized content. First of all, policy limits the content of Pay TV channel. The income of Pay TV channels of other countries are mostly depending on Gaming, Games and Adult programs. While in China, the R-rated programs are not allowed even in Pay TV channels. Therefore, the current Digital Pay TV channels have no advantage in content.

Secondly, there are policies to restrain the introduction of overseas channels. SARFT (The State Administration of Radio Film and Television) put strictly restriction on the broadcasting of foreign satellite channels, which is only allowed, with the encryption inside the CATV (Community Antenna Television) Network, in hotels, foreign-related institutions, scientific research unit that conform to the viewing conditions. For instance, that the Phoenix Satellite TV, Asia Television Limited have grounded in Guangdong Cable TV Network, and Dalian Cable TV Network also gets the permit of SARFT to transmit overseas TV programs, is not a sign that SARFT is liberalizing the restrictions of overseas TV channels transmissions, but only special cases of overseas channels' breakthrough into limited areas in mainland China. In October 2002, Xiamen Cable Digital TV launched. For the promotion of market, it launched Phoenix Chinese Channel, Phoenix InfoNews Channel, MTV, Sun TV, AXN and has received notable effect. But in the end, in July 2003, these overseas channels were forced to be off the shelf. In addition, according to Administrative Regulations of the Introduction \& Broadcasting of Overseas Television Programs by SARFT (the 42nd order of SARFT), in effect on October 23, 2004, stipulates that approved overseas TV programs should be repackage and re-edit and should not broadcast as a column directly in a fixed period (Overseas TV Programs Introduction \& Broadcast Management Regulations).

\section{Variety Ways to Promote the Content Supply}

That content is king, is the successful experience not only of free television channels, but also of Pay TV channels. To create a professional, personalized Pay TV channel, should adopts a variety of channels to promote the content:

\subsection{Implementation of the Separation of Production and Broadcast as the Main Body}

Separation of manufacture and Broadcast should be the main body, instead of a supplement of TV industry. Considering current development of TV industry, practices of manufacture and broadcast reform basically have 3 kinds. First is to separate column manufacturing as a unit; Second is to separate channel manufacturing and operating as a unit; Third is to restructure and strip the internal production apartment in TV station.

The basic feature of commercial television broadcast system model of the United States, Japan and many other countries is secondary dynamic mesh structure of network and affiliated stations, at the same time, the television stations would buy a certain quantity of programs from syndicate market. The interdependent tension between network and affiliated stations dominates the whole relationship. Affiliated stations would reach an agreement with TV network on profit distribution of program production, broadcast, advertising sales and so on. Network agrees to offer exclusive programs and provide certain compensation to the affiliated stations. Affiliated stations, and in return, would take up about three-quarters of program of TV Network as the advertising time. Since the $1970 \mathrm{~s}$, western countries added restrictions on network production monopoly, and promulgated related laws and regulations to encourage independent program Production Company, for the promotion of the diversification in TV production.

In the United States, for example, the network's economic strength is too strong in the 1970s. The implementation of Combination of Manufacture and Broadcast enabled the network to control production, sales and broadcast industry chain of TV programs. This kind of vertical integration had brought about bad effect on the competition environment for television industry and syndicated programs market suffered a major blow. In order to break the monopoly of three networks and improve the diversity of the programs, in 1970 to 1995, the FCC published Financial Interests and Syndicated Act, forcing three television networks to buy great deals of programs from independent TV program producers. At the same time, in 1971 to 1996, FCC has issued a golden time access regulations, limiting programs in golden time provided by TV networks for affiliated station.

The frame designed, which tried to prevent the vertical integration of powerful network monopoly the entire supply chain of TV industry, encouraged new program producers and distributors to join into the television industry, 
reducing the program control of Network to affiliated stations, improving the competitiveness of program production, making TV program production depart from television broadcast apartment. In the $1990 \mathrm{~s}$, with the rise of Fox and other Networks, and the emerge of cable TV, satellite TV and Internet, the number of audiences to the three conventional televisions sharply dropped and therefore two regulations were immediately abolished (Xiao, Yefei \& Yi, Yin, 2010).

Compared with the development of Separation of Manufacture and Broadcast in foreign countries, China couldn't really implement Separation of Manufacture and Broadcast due to excessive considering on ideological control and television department's existing interests, resulting in especially the supply shortage and poor quality of Pay TV channels, which lead to the mismanagement of Pay TV and eventually prevent the quality of the programs from improvement. Therefore, only when Separation of Manufacture and Broadcast was adopted and the development of private television production institutes was allowed and supported, could the programs of Pay TV channel realize effective supply

\subsection{Homemade Original Program}

Pay TV channel should first highlight original and irreplaceable programs, secondly actively create conditions for channel and tailor attractive innovative programs to form this channel's own characteristics. These programs must meet the special needs of audiences, and unique in existing resources block structure and unable to find through other channels. Homemade program can help to establish the authority of content and resources monopoly, forging programs not replicable that often a hit when broadcasting. Foreign Pay TV channels mostly have their own original program department (Original Programming), specifically responsible for the planning and development of movie, TV series, documentary and many other original content. Some programs of the United States Pay TV channels have already achieved great success with original TV dramas, like Prison Break, Lost, Sex and the City, Desperate Housewives, and the original talent show, like American idol, So You Think You Can Dance, etc. These are good examples for domestic market, and even many television stations of other countries all over the world follow after. $\mathrm{HBO}$, with its excellent original products, created several ratings legend in the United States, outshining the ABC, $\mathrm{NBC}$, and other national TV stations.

In addition to focusing on content, homemade original programs should also pay attention to the style. Style is a kind of aesthetic, originally referring to the comprehensive overall characteristic shown in literary creation. For a piece of work, it may has its own style; for a writer, it may has personal style; for A genre, an era, or a national literature, there is a genre style (or genres), age style and national style. The most important one is the personal style of writers. Different style is the way works by different writers be distinguished, as well as the symbol of recognition and understanding of literature in different genres, times, ethnic. For TV media, it must have high degree differences to stand out in program production with distinguishing style.

For example, Phoenix TV persists in "To make difference through different face", creating programs of high grade, the sense of times, rich impact and influence. The Early Phoenix Bus of early Phoenix had broken two habits of people. One is to switch the habit that people get information in the morning by reading newspapers or listening radio to watching television. Another is to make the habit of watching TV in evening to extend to the morning. The Early Phoenix Bus also reforms the traditional news broadcasting to news speaking. The way that the Phoenix inserts newspaper in TV has formed it its own style through this kind of innovative TV show, which is a contribution of the TV programs production, and at the same time not only achieved operation cost reduction, but increase awareness and preference of the audiences to Phoenix TV. Besides, the Phoenix satellite TV also insists that "Humanistic Care" as their program ideal and goal, to maximum the respect of people's limited right to be informed. It conveys the news as much as possible to the public, and unfolds the objective facts as much as possible to the society. Chen Xiaonan hosted Leng Nuan Ren Sheng (Life with Cold and Warmth). "Cold", namely the cold, hunger, darkness, abandoned; "Warm" is the indomitable vitality characters of the bottom-class and the blob of hope in their hearts. Phoenix satellite TV also breaks the traditional TV production mode, extending a new TV culture. That is, to encourage individual personalities, highlighting the pursuit of personality, giving the audience a completely new sense. In 2004, phoenix TV employed Li Ao with high salary to independently host the column Li Ao Have Something to Say, making personal adventurous points in the show. Host Li Ao talks about nearly everything, from Taiwan politics, society, economy, to research study, life and women, analyzing the political change of Taiwan over last 50 years, the fact of nowadays Taiwan society, relations between the Taiwan with Mainland as well as the dark side of the characters inside Chinese.

\subsection{Cooperative Programs Production with Social Institution}

Pay TV channels have high command for professional programs, which could not be satisfied by simply depending 
on radio and television homemade programs. Therefore, to expand program resources, that is to buy or exchange cooperative programs with social institutions, becomes the foundation of Pay TV channel. The expansion methods of programs of traditional television channels have more comprehensive development in the Pay TV channels. Jiangsu Dressy Channel (Liang Zhuang), for example, cost as high as millions of yuan monthly on program production. In order to strengthen the internationalism, Dressy Channel spends a large amount of money on close cooperation with Tang Long International Media company, the copyright agent of the French Fashion TV in China, to increase the individuation, and brought the global fashion into thousands of households, enabling the audiences be synchronized with the whole word at any time and never leave home. In June 2004, Dressy Channel was awarded Best Program Supply at the first China Digital TV Public Selection. In September 2004, in a survey of Sohu IT channel on" channel that interests you most and attract you to buy ", Dressy Channel ranked first among the provincial Pay TV. Dressy Channel would rely on its advantage as a professional fashion media to hold a series of big fashion activities, aiming to build a globalization fashion industry platform, and become a digital professional channel which majority of users in fashion would chose and the first fashion TV brand in China Mainland. In Chinese character, Liang, means shining beautiful expression. Zhuang, means both thick makeup or weak one are fitting. Dressy Channel makes life beautiful with fashion, and always keeps up with the international population (Introduction of Jiangsu Satellite Channel and Dressy Channel).

According to relevant Pay-TV policy management regulation, social institutions can participate in Pay TV channel operation, which not only ensures the capital that initial operation that required a large number of investments, but also brought the mercerization operation experience for itself. This laid the foundation of the opening of content, development of derived business, mercerization promotion of Pay TV channel and, therefore becomes the multitudinous pay TV channel choice. For Instance, Lucky Shopping channel was launched by Jilin television and Home Shopping Shanghai Limited (Short for TVSN) in form of cooperation. All the programs are produced by TVSN, and Jilin TV is responsible for the planning and broadcasting. TVSN guarantee thorough and rich logistics. Motorcycle Channel found by Chongqing TV is cooperated with You Tong Digital Media of SMI Corporation. SMI participate in program production and channel management. And Yi Tan Chun Qiu (Go Forum) channel is a professional go digital television channel found by the cooperation of BAMC and Mei Jia Media. These are the active exploration in cooperation business for Pay TV channel.

\subsection{Integration of the Existing Program Resource}

Pay TV channel should make full use of the current program resources and in many of the resources, the most important one the cumulative original TV program ones. In the past decades, large number of programs of Chinese television would be stored after being used only one or two time. And after decades of accumulation, the resources can be fully recycled and make them more objective by segmentation. The CEO of Softbank Asian fund YanYan once said: "The Chinese television market is the world's largest, at the same time the most segmental one." (Tan Tian, 2005) In the aspect of the content of program, "the most segmental market" means that the TV stations produce and sell programs all by itself, where many programs were broadcasted once then stored into tape library and never enter the market again, causing a serious waste. Therefore, all the old programs in TV stations of every level should be got together into one unified platform, for resources integration and to produce more professional programs.

HBO Pay TV of the United States, for example, brought classic movies in low cost and rearranged the film for broadcast as an movie professional channel in the initial development period. When it achieved a certain level of specialization, it then buys more differential production and optimal programs. In another example, Pay TV channel found by CCTV can use existing program resources freely, and all it's going to do is just to integrate and rearrange. Take the CCTV Digital Pay TV Strom series. Feng Chang (The Wind Field) and NO.1 Theatre are based mostly on old TV series, Selection of CCTV is simply the collection of old columns. Although there is no new content in these sources, but it can integrate the sinking resources, and reduce the high cost on homemade programs and on buy existing shows.

In the process of the existing program resource integration, the program selection should be attached great importance, and the improvement of program editing, layout, packaging alike. That is to say, selecting existing programs should be according to professional positioning and broadcast requirements of Pay TV channel, and implement secondary processing, packaging and utilization. For the program resource reutilization is actually the second creation. Rearrangement brings benefit, making good use of the program resources and refining the selling point. Unique layout combination and package maximize the development of the program resources in dust and obtain the most effective promotion of strong rebroadcast programs. In addition, new ones are different with the original channels in certain extent, making the audiences find everything new and fresh as well as making up for the shortage of programs, greatly attracting target users. This can yet be regarded as an economic, convenient and 
effective way to improve the quality of digital Pay TV channel program at present.

\subsection{Buy Domestic Programs}

The core content of program that owned copyright includes not only the self-made programs, but also exclusive buyout programs. Lager the number of these programs, stronger the strength of Pay TV channel. There are so ways as following: (1) to buy domestic programs for digital Pay TV channel. Finished programs purchased from manufacture institutions have more options, which can be buy and play, and lower the production cost. But at present, the television product market in mainland China is still non-standard. TV production institutes are of different levels, and the difference among quality of programs is big. Therefore, in the purchase, you must choose those excellent programs that have backup by production institutes with strength. In fact, when creating the core content, regardless of homemade or purchased one, there is a concept:"Resource is king". To achieve exclusiveness and scarcity, you must monopoly resources, namely monopoly the materials and theme resources of program. British Sky Television Station (BSkyB) is now Britain's most successful Pay TV channel operators, whose history is the English Premier League history. It is because of the monopoly of the broadcasting right of EPL that the BSkyB can reach such fast development, and achievement of nowadays. In return, it is because of BSkyB, football players like David Beckham can become stars. Therefore, to purchase the exclusive right of some boutique and popular programs for monopoly is feasible for forming the unique core content of the channel. Such as CCTV exclusively buyout the TV drama Jinghua History; Hunan satellite TV exclusively buyout Korean drama Dae Jang Geum; Guizhou Tian Yuan Go channel monopoly the go game resources, etc.

\subsection{Introducing Foreign Programs}

Simple relying on our own limited TV program production capacity to meet the needs of Pay TV channel and form attractive content as advantages is of much difficulty in a short time. What's more, in this process, the shortage of programs would result in the loss of subscribers, which will not only be conducive to the growth of digital Pay TV channel, but also not conducive to the development of television industry. Meanwhile, nowadays overseas TV programs are of numerous number, rich content, relatively specialization and highly originality and creativity, which can satisfy the user's curiosity, intellectual desire and excitement. So to our country, the appeal of foreign programs is very great, which has great potential. Therefore, it would be an effective way for the program providers of domestic Pay TV channel to introduce and integrate overseas excellent program resource within the range that policy allows. The introduction of foreign capital program can solve digital pay TV program content shortage problem to certain extent, and also bring vitality. China DTV Production Co. (short for CDP) broadcast original programs of HBCO in NO.1 Theatre channel for 6 hours every day, where the audiences can enjoy the latest, original HBO programs, including the films and TV series exclusive by HBO. It clarifies the difference between the digital Pay TV channel and free television channel, and solved the short board-- content of Pay TV channel, attracting a large number of users, and helps NO.1 Theater to maintain high market share and good image.

\section{References}

Gong, Jianghui. (2008). From the Specialization to Personalization of TV Channels, TV Research, 02, pp.40-41.

Li, Yang \& Sheng, Yu. (2009). Current Situation of Digital Pay TV Channels, Journalism \& Communication, 09, p.20.

Overseas TV Programs Introduction \& Broadcast Management Regulations, [Online] Available: http://www.mofcom.gov.cn/aarticle/b/g/200412/20041200320478.html.

SoHu Web: Introduction of Jiangsu Satellite Channel and Dressy Channel, [Online] Available: http://women.sohu.com/20050819/n240274424.shtml.

Tan, Tian, (2005). 2004 Chinese TV Content Industry Report, Voice and Screen World, 05. [Online] Available: http://www.sky.com/

Tang, Shiding \& Li, Bin, etc. (2005). Research on the Manufacture and Broadcast System Reform and the Development of TV Industry, Chinese Media University Press, p.03.

Tang, Shiding \& Li, Bin, etc. (2009). Mainland TV Industry Running Cigarette and Alcohol, China Radio International Press, p.226.

Xiao, Yefei \& Yi, Yin. Comparative Analysis of Chinese and Western Television Broadcast System, Media.

Xu, Yapwen. (2008, July 27.). The Media: Bright Future and Circuitous path of Digital TV, 21 CN: [Online] Available: http://finanee.21 en.eom/stoek/2008/06/27/4889389

Yin, Liangrun. (2009). How to Fill the Financing Gap of Digital TV Industry-From the aspect of Industrial Policy, Journal of Zhejiang Institute of Media, p.41. 